\title{
A Low-Loss 16-Channel Polarization Dispersion-Compensated PHASAR Demultiplexer
}

\author{
C. G. M. Vreeburg, C. G. P. Herben, X. J. M. Leijtens, M. K. Smit, \\ F. H. Groen, J. J. G. M. van der Tol, and P. Demeester
}

\begin{abstract}
An improved technology for realizing high-quality PHASAR's is reported, which is compatible with the integration of electrooptical switches for use in add-drop multiplexers. This technology is demonstrated in a 16-channel polarization independent low loss $(<2.4 \mathrm{~dB}$ on-chip) PHASAR.
\end{abstract}

Index Terms - Demultiplexer, integrated optics, PHASAR, semiconductor waveguides, wavelength-division multiplexing.

\section{INTRODUCTION}

$\mathbf{C}$ OMPLEX integrated routing devices such as add-drop multiplexers (ADM's) and optical-crossconnects (OXC's) are key components in advanced WDM networks. Recently, we published a four channel reconfigurable ADM [1]. It was composed of a PHASAR acting both as demultiplexer and multiplexer and four Mach-Zehnder interferometer switches.

This first prototype was not polarization independent. As a next step we try to make both the switches and the PHASAR polarization independent. An important issue in searching for ways to make the sub components polarization independent is the fact that all components still have to be integrable with each other. For this reason we have chosen to make the PHASAR polarization independent by applying the polarization dispersion-compensation approach as proposed and demonstrated by Takahashi [2] and Zirngibl [3]. In this technique a waveguide section with a birefringence different from the original waveguide is inserted in each array arm of the PHASAR. The length of this section is chosen in such a way that it compensates for the birefringence of the original waveguide. In an earlier publication [4], we already applied this polarization dispersion-compensation scheme, by locally removing the InP cladding layer of the waveguides. However, for TM-polarization an additional loss of $2 \mathrm{~dB}$ was encountered with respect to TE-polarization due to the mode

Manuscript received September 8, 1997; revised November 14, 1997. This work was supported in part by the ACTS AC-065 project BLISS.

C. G. M. Vreeburg, C. G. P. Herben, X. J. M. Leijtens, and M. K. Smit are with the Faculty of Electrical Engineering, Delft University of Technology, NL-2600 GA, Delft, The Netherlands.

F. H. Groen is with the Research Group for Optics, Department of Applied Physics, Delft University of Technology, NL-2600 GA Delft, The Netherlands.

J. J. G. M. van der Tol is with the KPN-Research, Royal PTT Netherlands N.V., NL-2260 AK Leidschendam, The Netherlands.

P. Demeester is with the University of Gent-IMEC, Department of Information Technology, B-9000 Gent, Belgium.

Publisher Item Identifier S 1041-1135(98)01842-4.

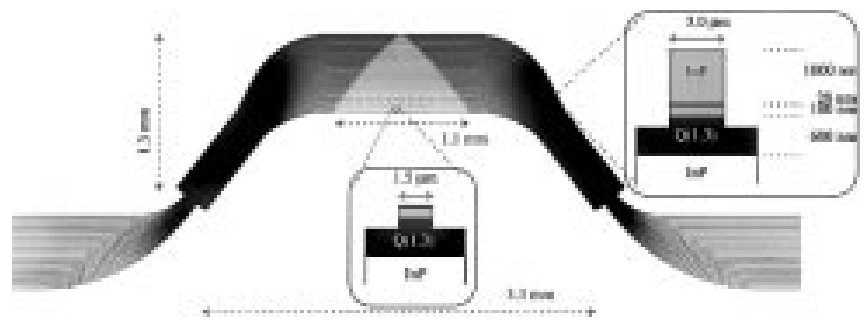

Fig. 1. Layout of the PHASAR demultiplexer and dimensions of the two waveguide structures in the array of the PHASAR.

mismatch between the two waveguide structures and the high propagation losses in the polarization dispersion-compensating waveguide. In this letter, we present an improved technology to overcome this additional loss. Instead of removing the whole cladding layer in the compensating waveguides, we only remove a part of it while at the same time we reduce the waveguide width to achieve sufficient difference in birefringence between both structures.

A 16-channel polarization compensated PHASAR has been fabricated using this improved technology. On-chip losses are as low as $2.0 \mathrm{~dB}$ for $\mathrm{TE}$ and $2.4 \mathrm{~dB}$ for TM-polarization, crosstalk is better than $-20 \mathrm{~dB}$ and the residual polarization dispersion is $<0.2 \mathrm{~nm}$.

\section{DESIGN}

Polarization dispersion compensation in a PHASAR can be achieved by inserting in each arm of the array a waveguide with a birefringence different from the original waveguide, as shown in Fig. 1. The polarization dispersion of the original waveguide structure can be compensated for by choosing the length increment $\delta l$ of the polarization dispersioncompensating section according to

$$
\delta l=\frac{\Delta N}{\Delta N-\Delta N} \cdot \Delta L
$$

with $\Delta L$ the length increment of the array arms and $\Delta N(=$ $\left.N_{\mathrm{TE}}-N_{\mathrm{TM}}\right)$ and $\Delta n\left(=n_{\mathrm{TE}}-n_{\mathrm{TM}}\right)$ the birefringence of the original structure and the compensating waveguide structure, respectively, [2], [3]. The larger the difference in birefringence between the original waveguide and the compensating section the smaller this compensating section can be.

Starting from the original waveguide structure as in Fig. 1, we have to find a compensating waveguide structure with a 


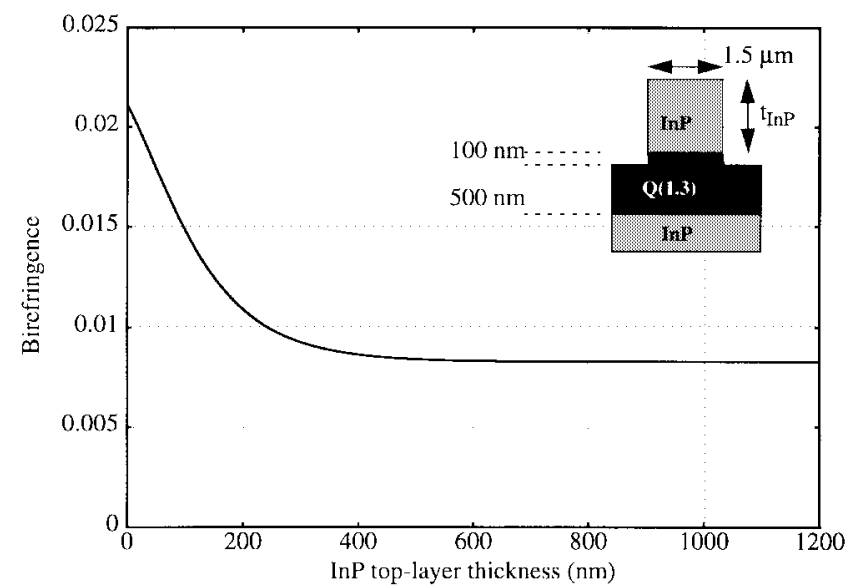

(a)

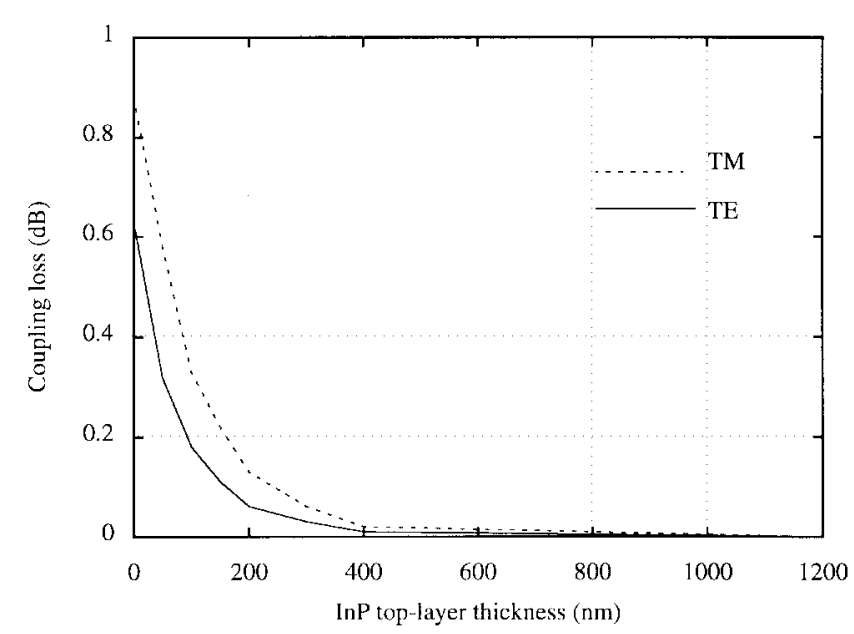

(b)

Fig. 2. (a) Birefringence and (b) coupling loss between the two waveguide structures as a function of the InP layer thickness of the waveguides in the triangular section (width $=1.5 \mu \mathrm{m}$ ).

different birefringence. First we reduced the waveguide width to $1.5 \mu \mathrm{m}$. This is the smallest width avoiding phase errors due to process deviations, and having acceptable propagation losses. The lateral transition can be regarded lossless since we use a $50-\mu \mathrm{m}$ linear taper to gradually change the width. The change in width decreases both the effective index of the TE mode as well as the TM mode. Since the reduction in effective index is larger for TM than for TE the birefringence increases.

In order to further increase the birefringence, we also have to remove some of the InP cladding layer. In Fig. 2 the birefringence and coupling loss between the two waveguide structures as function of the InP cladding layer is depicted. It clearly shows that the birefringence strongly increases when the InP cladding layer is removed, however the same holds for the coupling loss. As a compromise between coupling loss and birefringence we have chosen for a 200-nm InP cladding layer in the birefringence compensating structure. Measured polarization dispersion the original waveguide structure (3.0 $\mu \mathrm{m}$ wide with a $1.2-\mu \mathrm{m}$ InP cladding layer) and the compensating waveguide structure $(1.5 \mu \mathrm{m}$ wide with a $0.2-\mu \mathrm{m}$ InP cladding layer) were 3.1 and $5.7 \mathrm{~nm}$, respectively. From these

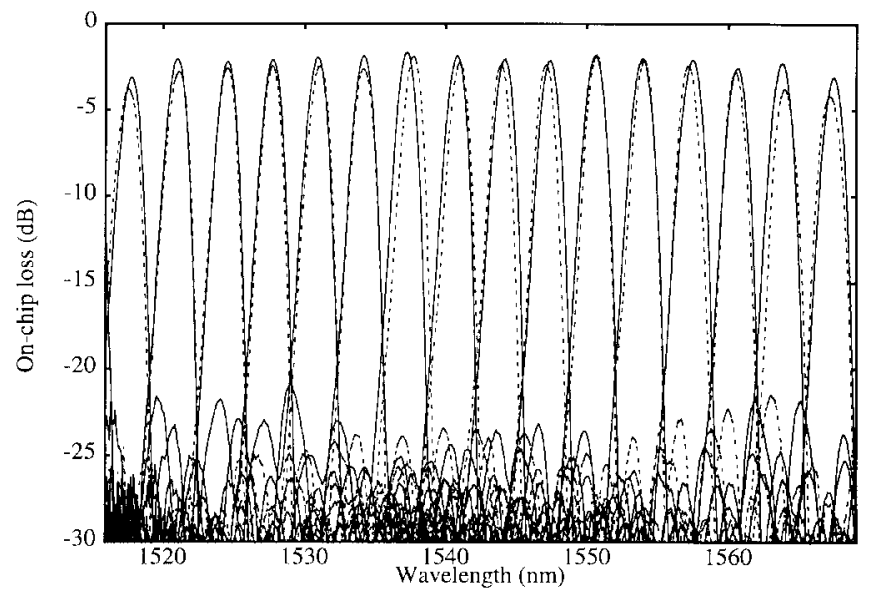

Fig. 3. Spectral response of the PHASAR for all 16 channels and both polarization states.

values we can calculate the birefringence in both structures; $\Delta N=0.07$ and $\Delta n=0.013$.

We designed a 16-channel PHASAR with a channel spacing of $400 \mathrm{GHz}(3.2 \mathrm{~nm})$ and a free-spectral-range of $51.2 \mathrm{~nm}$ resulting in an armlength difference $\Delta L=12.07 \mu \mathrm{m}$. Using the values for the birefringence calculated from the measured polarization dispersion in both waveguide structures we find a compensation length difference $\delta l=15 \mu \mathrm{m}$. The layout of the resulting PHASAR is depicted in Fig. 1. The device size, excluding access waveguides, is $3.3 \times 1.3 \mathrm{~mm}^{2}$.

\section{FABRICATION}

The PHASAR was fabricated in a MOVPE grown layer stack as shown in Fig. 1. A 100-nm-thick PECVD-SiN layer served as an etching mask for the waveguides. The pattern was defined using contact illumination with positive photoresist and transferred in the SiN-layer by $\mathrm{CHF}_{3}$ reactive ion etching. The waveguides were etched employing an optimized $\mathrm{CH}_{4} / \mathrm{H}_{2}$ etching and $\mathrm{O}_{2}$-descumming process as described in [5]. The InP cladding layer of the waveguides in the compensation section was etched through an opening in the photoresist mask. First, the SiN mask was removed by $\mathrm{CHF}_{3}$ reactive ion etching and finally the InP was wet chemically etched with a selective etch $\left(\mathrm{HCl}: \mathrm{H}_{3} \mathrm{PO}_{4}=1: 4\right)$ up to the $Q(1.3)$ etch stop layer. After removal of photoresist wafer processing was finished.

\section{EXPERIMENTAL RESULTS}

The PHASAR was measured using an EDFA as a broadband unpolarized light source. A polarizer was used to select the polarization. Light was coupled into the antireflection (AR)coated chip using microscope objectives and coupled out of the device by a single mode lensed fiber. This light was analyzed using an optical spectrum analyzer. Propagation losses of $3-\mu \mathrm{m}$-wide reference waveguides are $1.5 \mathrm{~dB} / \mathrm{cm}$ for both polarizations. Fig. 3 shows the response of all sixteen channels of the PHASAR for both polarizations. Average on-chip loss for TE- and TM-polarization is 2.0 and $2.4 \mathrm{~dB}$, respectively. The small difference in loss that still exists between TE and 
TM is caused by the junction between the two waveguide structures [see Fig. 2(b)]. Channel uniformity is better than $0.5 \mathrm{~dB}$ for the central 12 channels. Channel crosstalk is better than $-20 \mathrm{~dB}$. Residual polarization dispersion of all channels is smaller than $0.2 \mathrm{~nm}$. This residual polarization dispersion is caused by variations of the effective index along the wafer. It can be eliminated if the effective index is determined close to the PHASAR that has to be compensated.

\section{CONCLUSION AND Discussion}

An improved technology for eliminating polarization dispersion in integrated PHASAR demultiplexers has been demonstrated. A 16-channel polarization independent PHASAR demultiplexer with loss-figures comparable to silica-based devices has been realized in InP. Waveguide structure and fabrication process are compatible with wavelength routing devices such as OXC's and ADM's, as reported by us earlier. On-chip losses are smaller than $2.4 \mathrm{~dB}$ for both polarizations and the residual polarization dispersion is less than $0.2 \mathrm{~nm}$. This type of PHASAR in combination with polarization independent Mach-Zehnder interferometer switches [6] allows for the realization of polarization independent ADM's and OXC's.

\section{ACKNOWLEDGMENT}

A. Suurling and A. Looyen are acknowledged for EBPG mask fabrication and AR-coatings, respectively.

\section{REFERENCES}

[1] C. G. M. Vreeburg, T. Uitterdijk, Y. S. Oei, M. K. Smit, F. H. Groen, E. G. Metaal, P. Demeester, and H. J. Frankena, "First InP-based reconfigurable integrated add-drop multiplexer," IEEE Photon. Technol. Lett., vol. 9, pp. 191-193, Feb. 1997.

[2] H. Takahashi, Y. Hibino, Y. Ohmori, and M. Kawachi, "Polarizationinsensitive arrayed-waveguide grating multiplexer with birefringence compensated film," IEEE Photon. Technol. Lett., vol. 5, pp. 707-709, June 1993.

[3] M. Zirngibl, C. H. Joyner, and P. C. Chou, "Polarization compensated waveguide grating router on InP," Electron. Lett., vol. 31, no. 19, pp. 1662-1664.

[4] C. A. M. Steenbergen, C. van Dam, A. Looijen, C. G. P. Herben, R. de Kok, M. K. Smit, J. W. Pedersen, I. Moerman, R. G. Baets, and B. H. Verbeek, "Compact low loss $8 \times 10 \mathrm{GHz}$ polarization independent WDM receiver," in Proc. 22nd Eur. Conf. on Optical Communications (ECOC'96), Oslo, 1996, pp. 1.129-1.132.

[5] Y. Oei, L. H. Spiekman, F. H. Groen, I. Moerman, E. G. Metaal, and J. W. Pedersen, "Novel RIE-process for high quality InP-based waveguide structures," in Proc. 7th Eur. Conf. Integrated Optics (ECIO'95), Delft, The Netherlands, 1995 , pp. 205-208.

[6] T. Uitterdijk, C. G. M. Vreeburg, D. H. P. Maat, F. H. Groen, H van Brug, and I. Moerman, "Dilated, polarization insensitive InP-based space switch," in Proc. 8th Eur. Conf. Integrated Optics (ECIO'97), Stockholm, Sweden, 1997, pp. 551-554. 